\title{
RELATIONSHIP BETWEEN NOISE AND PSYCHOLOGICAL COMFORT OF THE USERS IN THE COMANDANTE FERRAZ ANTARCTIC STATION
}

http://dx.doi.org/10.4322/apa.2014.084

\author{
Deborah Martins Zaganelli1, ${ }^{1,}$, Cristina Engel de Alvarez ${ }^{1}$
}

\author{
${ }^{1}$ Universidade Federal do Espírito Santo - UFES, Av. Fernando Ferrari, 514, Goiabeiras, CEP 29075-910, Vitória, ES, Brazil \\ *e-mail: debbiezaganelli@yahoo.com
}

\begin{abstract}
The Comandante Ferraz Antarctic Station is a base camp and working place, housing a diversity of individuals in a restricted environment. Comfort is an essential criterion for the residence time to be effectively productive, in particular in relation to acoustics. The relevance of this study is based on the correlation between noise levels data and potential effects on the human body, in addition to contributing to the creation of noise prevention methods. The purpose of this paper is to assess the impact of noise levels on psychological comfort of the researchers of that Station. The data was gathered in situ, during XXVIII Antarctic Operation, according to the Brazilian Technical Standard for measurement procedures and additional parameters developed for the Station. Then, the systematization and analysis were carried out, and subsequently a mapping with mean noise levels was developed and the potential correlations with physical, physiological and psychological effects on human beings were verified. In some working environments the noise levels did not meet the comfort parameters; however they consider an 8-hour workday. In the remaining environments whose activities are of rest and work, only the adjacent outdoor points were analyzed, where the required isolation standards for sealing materials were found. Even though additional actions for further research were required, such as questionnaires and users physical evaluation, the outcomes obtained so far will serve as aid for the construction of new buildings that will make up the Station, with emphasis on the necessity of acoustic treatment of the environments to reduce noise from outdoor and indoor activities, especially in long term research locations.
\end{abstract}

Keywords: acoustic, noise, psychological comfort, Antarctic

\section{Introduction}

Sound is the propagation of mechanical energy through material medium in the form of wave motion, irradiated three-dimensionally in all directions. While sound has a defined frequency, noise is a vibratory physical phenomenon with undefined characteristics of pressure and frequency, disharmoniously mixed with each other (Grandjean, 1988 apud Abrahão et al., 2009). It is the ear that captures the sounds and noise vibrations, allowing communication and as well acting as an alarm system for the body. When the hearing system is exposed to high magnitude sounds and noises, not only is its function affected but it also results in physical, psychological and physiological harm. Longterm exposure can lead to hearing loss and extra-hearing disorders.
The purpose of this research was to assess the impact of noise levels on the psychological comfort of the researchers of the Comandante Ferraz Antarctic Station (EACF, Portuguese acronym). The hypothesis was that the noise levels generated by maintenance and operational equipment both outdoors and indoors at EACF may cause acoustic discomfort to the users.

The relevance of this study is based on the correlation between the noise level data, according to the environments, and the potential effects on the human body. It has also contributed with data to create prevention methods in buildings based in Antarctica, such as using techniques and materials that do not demand using noisy equipment for their maintenance and the specification of more silent 
operating equipment, and also ways to control noise, with materials such as acoustic isolation (soundproofing) of the environments that have transmitting equipment. This study also generates additional reflections that can be used outside the Antarctic environment, with application to the reality of urban spaces, for example. However, the great difference between the comfort conditions for an urban worker and the specific condition of the users of a Scientific Station are highlighted, where the stress situation and the confinement may contribute to enhance the sensation of discomfort.

\section{Materials and Methods}

The data was collected in situ by trained researchers from the Planning and Projects Laboratory of the Federal University of Espírito Santo during the XXVIII Antarctic Operation in a period of 15 nonconsecutive days (due to climatic variations), from 02 to 22 December 2009. The measurement procedure followed the recommendations of the Brazilian Technical Standard NBR 10151 (ABNT, 1987a) and a methodology developed specifically for EACF, because it is a different environment from the Brazilian one, where some additional parameters were set up such as compliance with factors compromising the reliability of measurements, according to Alvarez \& Yoshimoto (2004).

Initially, the identification of main sound sources that generate discomfort to users was undertaken and 13 and 10 points of outside and inside measurements were set up, respectively, as well as the measurement times: during daytime, with higher levels resulting from the operation of several types of equipment, and during night time, with lower sound levels. The equipment used was a digital sound level meter with calipers $\left(\right.$ Extech $\left.^{\mathrm{TM}}\right)$ set at weighing A. This setting has been justified in several studies showing that sound levels measured in $\mathrm{dB}(\mathrm{A})$ are the closest to the perceptual characteristics of human hearing (Grandjean \& Kroemer, 2005).

For the analysis of collected data, the mean and standard deviation values of the noise levels measured at each point were calculated in order to show their degree of variability. Then, the analysis of data for every environment was performed observing the variation during different collection days and during two periods, daytime and night time, as well as active noise sources at the time of the measurements. This was followed by acoustic mapping of EACF according to the comfort levels established by standard NBR 10152 (ABNT, 1987b). The data of the standard and measurement were overlapping and their differences were noted, and subsequently possible correlations with physical, physiological and psychological effects from noise on human beings were carried out.

\section{Results}

During the period of measurement, the main noise sources identified in the inner environments of the Comandante Ferraz Antarctic Station (EACF) were the electric power generators, located in the Machinery Room and Garage, and the air compressors of the Aquariums and Carpentry. In the outdoor environment, the noisiest were the vehicles tractor and boat - in operation, including all night on one of the days.

The largest variations in noise levels throughout the study occurred on days when two electric power generators had been replaced, mainly at point $\mathrm{B}$, in the Machinery Room, where the noise reduction was more significant in the days following the change of the electric power generators. It was also found that the operational equipment, such as generators, compressors and trash incinerator led to alterations in the noise level not only in the measurement environments, but also in the adjacent ones too.

It is noteworthy that the interior of the cabins was not considered, since the settings of reduced dimensions did not allow using the methodological determinants required by specific standard to use the sound level meter. However, the assessment of environment is considered to be of essential importance as negative effects of noise interferes with the length and quality of sleep, in addition acts indirectly leading to decrease of the daily performance of the human being, mainly in tasks requiring concentration. The collected data were systematized and appear in the Figure 1.

\section{Discussion}

When the data related to daytime and night time periods of measurement were compared, reduced noise mean value was found at some points. In general, the places of measurement are passage environments (points A, Garage; B, Machinery Room; C, Old Garage; E, Triage Room), except 
(๘)

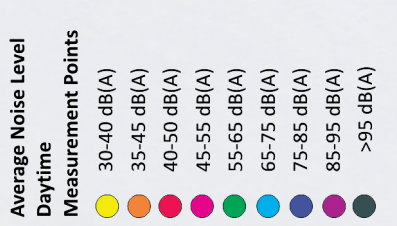

우

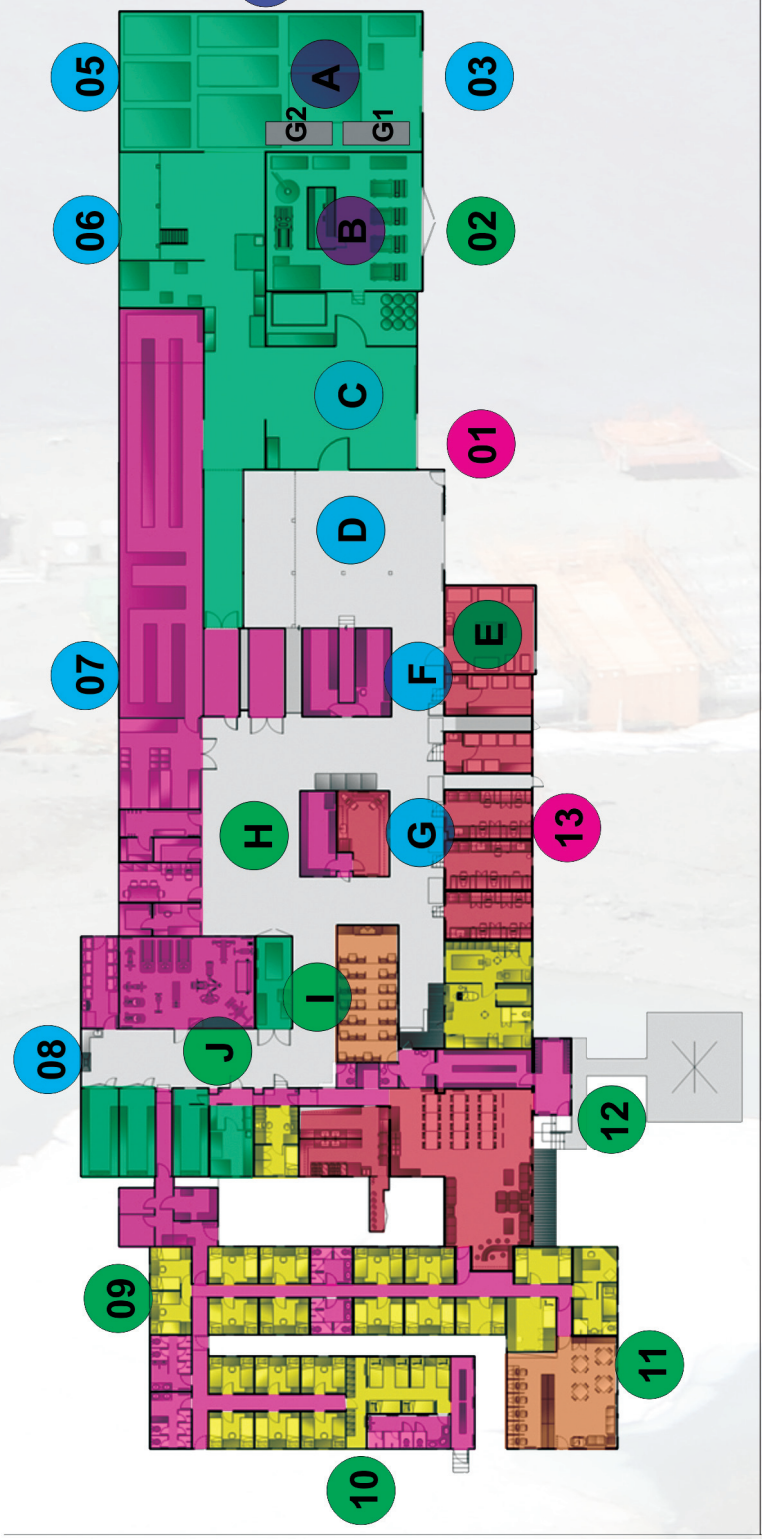

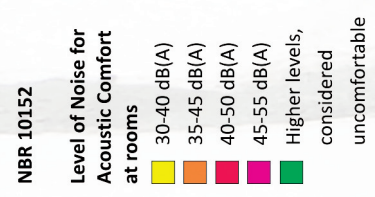

(2)

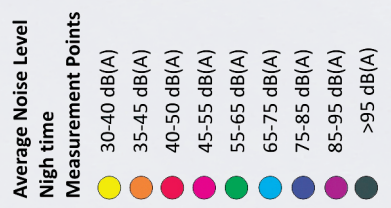

(
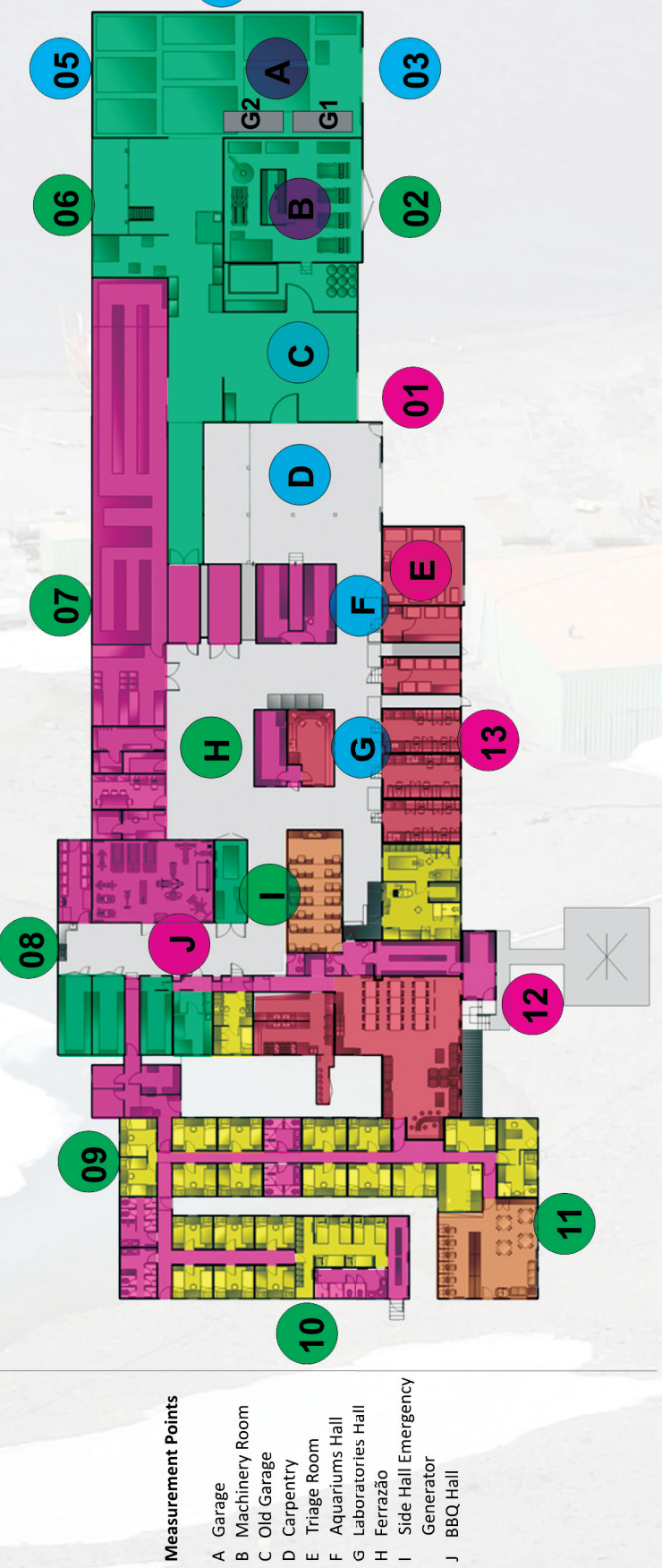

Figure 1. EACF acoustic mapping showing the (a) average daytime noise level and the (b) average night time noise level, compared with the NBR 10152. 
the points D (Carpentry) and E (Screening Room), where the standing time was lower.

In these places, the inner measurement of the environment could be ascertained, at which point $\mathrm{E}$ the mean noise levels during daytime and night time were $64.44 \mathrm{~dB}(\mathrm{~A})$ and $54.73 \mathrm{~dB}(\mathrm{~A})$, respectively, noting a decrease of $9.01 \mathrm{~dB}(\mathrm{~A})$ for the night time period. The standard deviation values showed a range of $3.84 \mathrm{~dB}(\mathrm{~A}) /$ daytime and $4.33 \mathrm{~dB}(\mathrm{~A}) /$ night time. The time of louder noise was during the measurement on December 12th, at $10 \mathrm{am}$, reaching $72 \mathrm{~dB}(\mathrm{~A})$ when impact noise (from a hammer) occurred in the Carpentry.

In order to adequate this environment to a level considered comfortable, $40 \mathrm{~dB}(\mathrm{~A})$, according to standard NBR 10152 (ABNT, 1987a), it would be necessary to reduce this average to $24.44 \mathrm{~dB}(\mathrm{~A}) /$ daytime and $14.73 \mathrm{~dB}(\mathrm{~A}) /$ night time. In order to achieve the level considered acceptable, 50 $\mathrm{dB}(\mathrm{A})$, it would be necessary to reduce $14.44 \mathrm{~dB}(\mathrm{~A}) /$ daytime and $4.73 \mathrm{~dB}(\mathrm{~A}) /$ night time. However, by applying the NR 15 (Brasil, 1978) the standing time in this environment could be an 8-hour working day, although it is already characterized as a situation of discomfort.

In the Carpentry (point D), higher sound level also was found on December $12^{\text {th }}$, at $10 \mathrm{am}$, recording $89.9 \mathrm{~dB}(\mathrm{~A})$. According to the mean of the environment of $72.33 \mathrm{~dB}(\mathrm{~A})$, the standing time inside it also could be an 8 -hour working day, as reported in the NR 15 , in a discomfort situation. Murgel (2009) have reported that exposure to noise levels above $70 \mathrm{~dB}(\mathrm{~A})$ may lead to sensitive neuropsychological changes whose symptoms are increased heart and respiratory rates and high blood pressure, effects from an alert and defense status to which the body is subjected. Above this level the body stress increases, and at around $100 \mathrm{~dB}(\mathrm{~A})$ there may be immediate loss of the hearing (Souza, 1992).

In the remaining points, the significance for analysis was to confirm whether the indoor working and rest environments needing less noise level and having higher standing time were in accordance with the recommendations of standard NBR 10152, such as the Cabins, Ward, Department of Communication, Library, Audio and Video Room and Laboratories. As the EACF is a Scientific Station, one aspect considered is that its environments are used both during daytime and night time periods, thus the levels should be compatible in both situations, since in these places the use of alternatives to protect the user against noise are difficult, such as using earplugs and controls to reduce the exposure time, are hampered.

By observing the measurement points next to the Cabins $(9,10,11$ e 12), at point 9 a decrease of $7.04 \mathrm{~dB}(\mathrm{~A})$ during the night time period was found; at points 10 and 11 an increase of $2.45 \mathrm{~dB}(\mathrm{~A})$ and $0.85 \mathrm{~dB}(\mathrm{~A})$, respectively were found; and at point 12 a decrease of $1.62 \mathrm{~dB}(\mathrm{~A})$ was noted. In order to adequate to the level of $35 \mathrm{~dB}(\mathrm{~A})$, the level considered comfortable according to NBR 10152 (ABNT, 1987b), would require sealing materials to isolate the external noise during the daytime period, reducing its level of transmission into the environment in $28.17 \mathrm{~dB}(\mathrm{~A}), 20.40 \mathrm{~dB}(\mathrm{~A}), 23.00 \mathrm{~dB}(\mathrm{~A})$ and $21.57 \mathrm{~dB}(\mathrm{~A})$, respectively at points $9,10,11$, and 12 . In order to achieve the level of $40 \mathrm{~dB}(\mathrm{~A})$, the level considered acceptable, would require a decrease of $23.17 \mathrm{~dB}(\mathrm{~A}), 15.40$ $\mathrm{dB}(\mathrm{A}), 18.00 \mathrm{~dB}(\mathrm{~A})$ and $16.57 \mathrm{~dB}(\mathrm{~A})$, respectively.

Hearing, being the first alert sense of the human being, is always active even during sleep and according to the World Health Organization (WHO, 1980), the effects of noise on sleep starts from $35 \mathrm{~dB}(\mathrm{~A})$, thus beginning of alertness. Above the mentioned level deep sleep time is reduced, in addition it extends beyond sleep time by a further 20 minutes for levels higher than $65 \mathrm{~dB}(\mathrm{~A})$ and up to 10 minutes for levels up to $55 \mathrm{~dB}(\mathrm{~A})$, according Murgel (2009). Thus, the importance of meeting the standard is noted, mainly in the dormitory environments, in order to ensure deep sleep, which is the most restorative sleep phase and which will allow the good performance of tasks on the following day.

In Laboratory and Library Rooms, which require intellectual work, the need to keep noise below $55 \mathrm{~dB}$ (A) is justified to avoid losses in productivity and the likelihood of errors in tasks requiring concentration and memory (Murgel, 2009).

In environments where intelligible verbal communication is important, such as the Department of Communication and the Audio and Video Room, it is recommended to keep the noise level up to $45 \mathrm{~dB}(\mathrm{~A})$, so that the conversation be performed in a normal tone of voice. When the level 
increases to $55 \mathrm{~dB}(\mathrm{~A})$ the speech recognition has become difficult, and when it reaches $65 \mathrm{~dB}(\mathrm{~A})$ a higher vocal effort is required. The necessary reductions in the daytime period in order to reach both the comfortable and the acceptable levels for theses environments to meet the standard, respectively, would be: in the Department of Communication, point I, $24.69 \mathrm{~dB}(\mathrm{~A})$ and $19.69 \mathrm{~dB}(\mathrm{~A})$; point $\mathrm{J}, 21.79 \mathrm{~dB}(\mathrm{~A})$ and 16.79 $\mathrm{dB}(\mathrm{A})$. In the Audio/Video Room, point G, $35.24 \mathrm{~dB}(\mathrm{~A})$ and $25.24 \mathrm{~dB}(\mathrm{~A})$; point $\mathrm{H}, 27.98 \mathrm{~dB}(\mathrm{~A})$ and $17.98 \mathrm{~dB}(\mathrm{~A})$; point I, $24.69 \mathrm{~dB}(\mathrm{~A})$ and $14.69 \mathrm{~dB}(\mathrm{~A})$; point $\mathrm{J}, 21.79 \mathrm{~dB}(\mathrm{~A})$ and $11.79 \mathrm{~dB}(\mathrm{~A})$. For the night time period, the reductions to reach both the comfortable and acceptable levels would be: Department of Communication, point I, $23.20 \mathrm{~dB}(\mathrm{~A})$ and $18.20 \mathrm{~dB}(\mathrm{~A})$; point $\mathrm{J}, 19.39 \mathrm{~dB}(\mathrm{~A})$ and $14.39 \mathrm{~dB}(\mathrm{~A})$. In the Audio/Video Room, point G, $35.04 \mathrm{~dB}(\mathrm{~A})$ and 25.04 $\mathrm{dB}(\mathrm{A})$, point $\mathrm{H}, 27.81 \mathrm{~dB}(\mathrm{~A})$ and $17.81 \mathrm{~dB}(\mathrm{~A})$; point I, 23.20 $\mathrm{dB}(\mathrm{A})$ and $13.20 \mathrm{~dB}(\mathrm{~A})$; point $\mathrm{J}, 19.39 \mathrm{~dB}(\mathrm{~A})$ and $9.39 \mathrm{~dB}(\mathrm{~A})$.

\section{Conclusion}

In order to measure the actual noise level from environments of the EACF the internal measurement of their rooms would be required, which was expected to occur in the summer of 2012/2013. However, on 25 February, 2012, a fire destroyed part of the EACF, creating discontinuity of all the studies. Thus, the data obtained and measured will serve mainly to aid in the preparation of the Reference Term that will guide the construction of new buildings that will comprise the EACF, standing out as desirable the need for more research regarding the sealing materials of environments and their contribution to isolation of the sources of noise, whether outdoors or indoors. The application of questionnaires to users for subjective assessing of the noise that points out psychological changes, as well as physical evaluations to verify the hearing thresholds of the users and the time of exposure to noises with the aid of professionals from other fields of science also would complement this research.

In environments directly analyzed, namely Carpentry and Screening Room, the mean noise levels showed differences with the standards parameters; thus, in the future specific solutions should be applied to reduce the noise. In these cases the options are: to reduce the noise at source, to diminish the noise in the environment where the source is located, to decrease the noise between the environment where it is produced and the other environment, or to minimize the noise at the own hearing organ. In environments indirectly analyzed, namely Cabins, Ward, Department of Communication, Library, Laboratories, and Audio/Video Room, further research of construction materials is recommended to achieve the correct measurement of indoor noise level.

Acoustic mapping is an important tool that can help in design decisions such as the location of noisy equipment, specification of less noisy equipment, use of materials with acoustic qualities and use of materials that do not require maintenance with noisy equipment.

\section{Acknowledgements}

This work integrates the National Institute of Science and Technology Antarctic Environmental Research (INCT-APA) that receive scientific and financial supports of the National Council for Research and Development (CNPq process: $\mathrm{n}^{\circ}$ 574018/2008-5) and Research Support Foundation of the State of Rio de Janeiro (FAPERJ $n^{\circ}$ E-16/170,023/2008). The authors also acknowledge the support of the Brazilian Ministries of Science, Technology and Innovation (MCTI), of Environment (MMA) and Inter-Ministry Commission for Resources of the Sea (CIRM).

\section{References}

Abrahão, J.; Sznelwar, L.; Silvino, A.; Sarmet, M. \& Pinho, D. (2009). Introdução à ergonomia: da prática à teoria. São Paulo: Blucher.

Alvarez, C.E. \& Yoshimoto, M. (2004). Avaliação de impacto acústico na Estação Antártica Comandante Ferraz: resultados preliminares. In: Anais da XV Reunion de Administradores de Programas Antárticos Latinoamericanos - RAPAL; 2004; Guayaquil. 
Associação Brasileira de Normas Técnicas - ABNT. (1987a). NBR 10151: Avaliação do ruído em áreas habitadas visando o conforto da comunidade. Rio de Janeiro: ABNT.

Associação Brasileira de Normas Técnicas - ABNT. (1987b). NBR 10152: Níveis de ruído para conforto acústico. Rio de Janeiro: ABNT.

Brasil. Ministério do Trabalho e Emprego. (1978). Norma Regulamentadora NR 15. Atividades e operações insalubres. Brasília: Ministério do Trabalho e Emprego.

Grandjean, E. \& Kroemer, K.H.E. (2005). Manual de ergonomia: adaptando o trabalho ao homem. Tradução de Lia Buarque de Macedo Guimarães. 5. ed. Porto Alegre: Bookman.

Murgel, E. (2009). Fundamentos de acústica ambiental. São Paulo: Senac São Paulo.

Souza, F.P. (1992). Efeitos da Poluição Sonora no Sono e na Saúde em Geral - Ênfase Urbana. Revista Brasileira de Acústica e Vibrações, 10: 12-22.

World Health Organization - WHO. (1980). Noise. Geneva: WHO. 